\title{
Erratum: A Behavioral Study of Promethazine Interaction with Analgesic Effect of Diclofenac: Pain Combination Therapy
}

\author{
Niloofar Amidi ${ }^{1}$, Zohreh Izadidastenaei ${ }^{2}$, Malihe Araghchian $^{1}$, Davoud Ahmadimoghaddam ${ }^{1}$ * \\ ${ }^{1}$ Department of Pharmacology and Toxicology, School of Pharmacy, Hamadan University of Medical Sciences, Hamadan, Iran \\ ${ }^{2}$ Neurophysiology Research Center, Hamadan University of Medical Sciences, Hamadan, Iran
}

Received May 22, 2019, Reviewed January 22, 2020, Accepted February 3, 2020

*Corresponding Author

Davoud Ahmadimoghaddam

Department of Pharmacology, School of Pharmacy, Hamadan University of Medical Sciences, 6517838678 Hamadan, Iran

Tel: +98-81-3838-1675, E-mail: davoud1980@yahoo.com

https://doi.org/10.3831/KPI.2020.23.003

Journal of Pharmacopuncture. 2020;23(1):18-24.

The original article "A Behavioral Study of Promethazine Interaction with Analgesic Effect of Diclofenac: Pain Combination Therapy" corresponded by Davoud Ahmadimoghaddam was published with incorrect p-value.

Every p-value for all tests in the Results section should be modified under 0.05 ( $\mathrm{p}<0.05$ ). 